\title{
Produtividade do amendoim obtido de cultivares arranjadas em sistema de cultivo
}

Submetido - 01 ago. $2020 \quad$ Aprovado - 04 set. $2020 \quad$ Publicado - 14 out. 2020
dol http://dx.doi.org/10.17648/sas.v1i2.87

\section{Graduanda em Agronomia - Universidade julienetecinformatica@gmail.com.}

Juliene Lariça Ferreira da Silva
Federal do Agreste de Pernambuco,

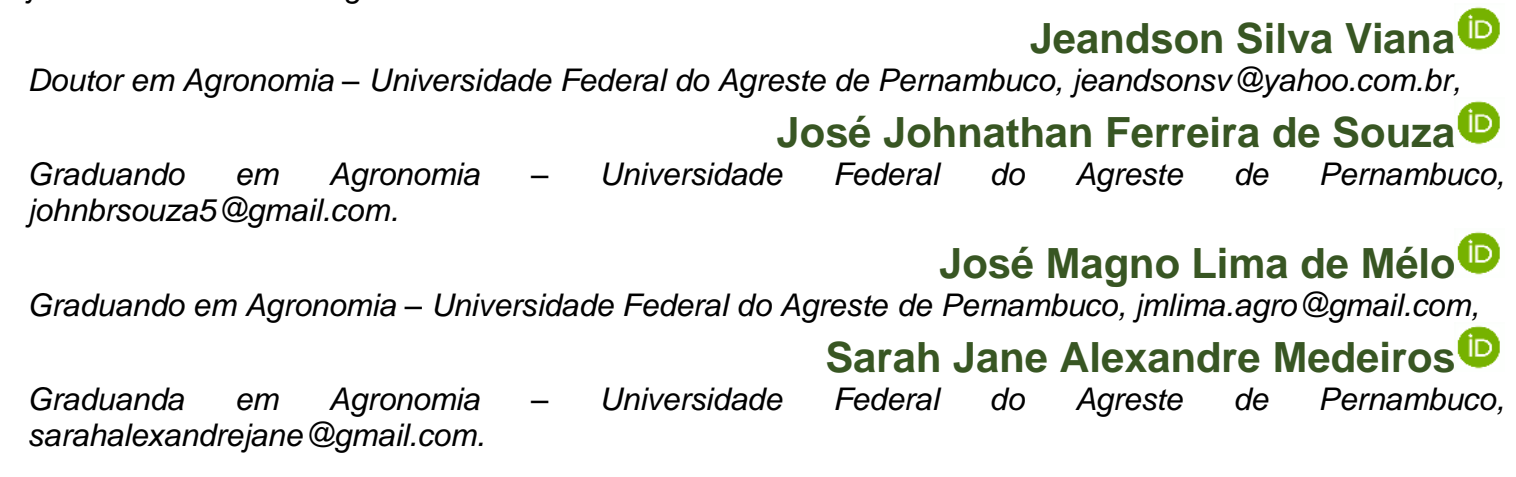

\section{RESUMO}

O amendoim (Arachis hypogaea L.) é uma das principais oleaginosas cultivadas no Brasil e no mundo e considerada uma das mais importantes culturas entre as leguminosas, ao lado do feijão e da soja. A produção deste vegetal no Brasil teve um crescimento considerável, pois também tem crescido o mercado de confeitarias e salgados, onde o amendoim é usado como complemento. A fim de suprir as necessidades do produtor e tornar rentável a produção de amendoim, instituições de pesquisa desenvolvem e disponibilizam para a produção cultivares de com características adaptáveis para determinadas regiões, no entanto o sucesso de uma cultura não depende apenas da escolha correta da cultivar mas também de outros fatores que afetam diretamente a produtividade e produção. $O$ presente estudo tem como objetivo testar cultivares de amendoim de crescimento ereto e prostrado e densidades de corte sobre a fitomassa e a produção do grão. $O$ amendoim foi cultivado em condições de campo, em delineamento em blocos ao acaso, em esquema de subsubparcela de 4x5x2, BR1, TATU ST (crescimento vertical), Runner IAC 886 e IAC 503 (crescimento prostrado) e as densidades de 8,11,14,17,20 e com e sem corte da parte aérea. As avaliações foram realizadas em condições de campo e laboratório, utilizando a amostra de 10 plantas por parcela. $O$ aumento da densidade proporcionou uma considerável elevação no número de ginóforos bem como na altura das plantas de porte ereto. $O$ corte associado à densidade correta para cada cultivar proporciona além do aproveitamento de quase toda a planta de amendoim, possibilita melhorias no desenvolvimento do vegetal, podendo assim aumentar sua produção e produtividade.

Palavras-chave: Densidade de plantio; Leguminosa; Grão; Fitomassa.

\section{Peanut productivity obtained from cultivars arranged in cultivation systems}

\author{
ABSTRACT
}


Peanut (Arachis hypogaea L.) is one of the main oilseeds grown in Brazil and in the world and considered one of the most important crops among legumes, alongside beans and soybeans. The production of this vegetable in Brazil has grown considerably, as the confectionery and savory market has also grown, where peanuts are used as a complement. In order to meet the needs of the producer and make peanut production profitable, research institutions develop and make available for production cultivars of with adaptable characteristics for certain regions, however the success of a crop does not depend only on the correct choice of the cultivar but also other factors that directly affect productivity and production. The present study aims to test peanut cultivars with upright and prostrate growth and cut densities on phytomass and grain production. Peanuts were grown under field conditions, in a randomized block design, in a 4x5x2 sub-plot scheme, BR1, TATU ST (vertical growth), Runner IAC 886 and IAC 503 (prostrate growth) and densities of 8.11, $14,17,20$ and with and without cut of the aerial part. The evaluations were carried out under field and laboratory conditions, using a sample of 10 plants per plot. The increase in density provided a considerable increase in the number of gynophores as well as in the height of plants of erect size. The cut associated with the correct density for each cultivar provides in addition to the use of almost the entire peanut plant, it allows improvements in the development of the plant, thus being able to increase its production and productivity.

Keywords: Planting densit; Legume; Grain; Phytomass.

\section{Productividad de mani obtenida de cultivares arregkados em sistemas de cultivo}

\section{RESUMEN}

El maní (Arachis hypogaea L.) es una de las principales semillas oleaginosas cultivadas en Brasil y en el mundo y considerado uno de los cultivos más importantes entre las legumbres, junto con los frijoles y la soja. La producción de este vegetal en Brasil ha crecido considerablemente, como también lo ha hecho el mercado de productos de confitería y salados, donde el maní se utiliza como complemento. Para satisfacer las necesidades del productor y rentabilizar la producción de maní, las instituciones de investigación desarrollan y ponen a disposición cultivares de producción con características adaptables para ciertas regiones, sin embargo, el éxito de un cultivo no depende solo de la elección correcta del cultivar sino También otros factores que afectan directamente la productividad y la producción. El presente estudio tiene como objetivo evaluar los cultivares de maní con crecimiento vertical y postrado y cortar las densidades en la producción de fitomasa y granos. Los cacahuetes se cultivaron en condiciones de campo, en un diseño de bloques al azar, en un esquema de subtrama $4 \times 5 \times 2$, BR1, TATU ST (crecimiento vertical), Runner IAC 886 e IAC 503 (crecimiento postrado) y densidades de 8.11, 14,17,20 y con y sin corte de la parte aérea. Las evaluaciones se llevaron a cabo en condiciones de campo y laboratorio, utilizando una muestra de 10 plantas por parcela. El aumento en la densidad proporcionó un aumento considerable en el número de ginóforos, así como en la altura de las plantas de tamaño erecto. El corte asociado con la densidad correcta para cada cultivar, además del uso de casi toda la planta de maní, permite mejoras en el desarrollo de la planta, lo que permite aumentar su producción y productividad.

Palabras clave: Densidad de siembra; Leguminosa; Grano; Fitomasa.

\section{Introdução}

O Brasil na década de 1970 foi considerado um grande produtor de amendoim de importância mundial, produzindo nos estados de São Paulo e

Paraná, estes que dominavam a produção de amendoim nacional em grande escala, sendo forte a produção de farelo para alimentação animal e óleo 
vegetal, este que teve papel ativo na introdução das gorduras vegetais na alimentação dos brasileiros. (FREITAS; MARGARIDO; NEGRI NETO, 2003).

Vários foram os motivos dos quais houve a queda de produção da cultura, dentre eles a susceptibilidade às oscilações edafoclimáticas, baixo rendimento por área, preços com grande oscilação e custo alto de produção. (NOGUEIRA JUNIOR, 1976), outro fato que levou a queda da produção da oleaginosa foi a elevação da produção de outras culturas como a soja, canade-açúcar e laranja nos estados de São Paulo e Paraná (FREITAS; MARGARIDO; NEGRI NETO, 2003). No entanto, produção deste vegetal voltou a crescer com a alta no mercado de confeitarias e salgados, essa demanda para o novo comércio requer uma melhor qualidade do produto, o que se torna necessário cultivares que atendessem bem os quesitos qualidade, e adaptação a fatores climáticos.

Nesse sentido Institutos de pesquisa deram origem à cultivares de amendoim utilizando técnicas de melhoramento genético, realizando-se testes para testar a eficácia das mesmas (Martins, 2006).

Contudo, o sucesso de uma boa produção não está apenas atrelado á escolha da melhor cultivar, Mauad et al. (2010) afirma que a produtividade de uma cultura é definida pela interação entre a planta, o ambiente de produção e o manejo. A densidade de plantio ou densidade de semeadura estimula a competição intra e interespecífica, seja por nutrientes, água ou mesmo espaço, com isso alterações morfológicas e fisiológicas podem ser observadas nas plantas (ARGENTA et al., 2001) O adensamento propicia também sombreamento ao solo, fazendo com que o solo reduza as perdas de água por evaporação, causando também uma barreira natural à germinação de plantas daninhas.

Outra maneira de induzir uma melhor produtividade da cultura é através do corte da parte aérea, que após ser realizado, a planta será estimulada a produzir uma maior número de vagens e grãos, pois a energia destinada à parte vegetativa, é direcionada para a parte reprodutiva da planta 
(TOLEDO et al., 2009), o que leva a associar altas densidades de plantio ao corte para o aumento da produtividade final bem como a utilização da massa do amendoim seja para alimentação animal, seja para adubação verde.

Visando o aumento da produção e produtividade, objetivou-se testar cultivares de amendoim de crescimento ereto e prostrado em diferentes densidades de plantio e corte da parte aérea.

\section{Material e métodos}

O experimento foi conduzido no ano agrícola 2018/2019, nos períodos das águas e da seca, no município de Garanhuns-Pernambuco (Agreste Meridional), com coordenadas $08^{\circ} 53^{\prime} 19^{\prime \prime} \mathrm{S}$ e longitude de $36^{\circ} 37^{\prime} 34^{\prime \prime} \mathrm{O}$, altitude de $958 \mathrm{~m}$. O solo da área experimental é classificado como Argissolo Amarelo de textura franco-argilo-arenoso possuindo uma composição química com ph: $5,6 \mathrm{mg} \mathrm{dm}^{-3}$, P: $27 \mathrm{mg} \mathrm{dm}^{-3}$, Mg: 0,7 cmolc $\mathrm{dm}^{-3}$, Ca: $1,2 \mathrm{cmolc} \mathrm{dm}{ }^{-3}$, Al: 0,0, Na: $6,0 \mathrm{cmolc} \mathrm{dm}^{-3}$ e K: 0,6 cmolc $\mathrm{dm}^{-3}$.

As avaliações de Altura de planta e Número de ginóforo foram realizadas em campo e Índice de Área Foliar e Produtividade em laboratório (CENLAG - Centro Laboratorial de Apoio à Pesquisa, da Universidade Federal do Agreste de Pernambuco, o amendoim foi cultivado em condições de campo, em delineamento em blocos ao acaso, em esquema de subsubparcela de 4×5×2, BR1, TATU ST (crescimento vertical), Runner IAC 886 e IAC 503 (crescimento prostrado) e as densidades de $8,11,14,17,20$ plantas por metro linear, com e sem corte da parte aérea.

As sementes foram adquiridas na EMBRAPA-Algodão e no Instituto Agronômico de Campinas (IAC).

O corte para a obtenção de fitomassa da parte aérea foi realizado a 15 cm do solo e produção de grãos foi realizado no período de maturação de cada cultivar. As avaliações foram realizadas na área útil, por meio das seguintes características agronômicas e utilizando a amostra de 10 plantas por parcela: 
a) Índice de Área foliar - Foi analisada através de um equipamento integrador de área foliar aos 30 dias após estabilização da emergência (FLOSS, 2004).

b) Altura de plantas: Feita com auxílio de trena

c) Número de ginóforos

d) Produtividade

Os dados foram analisados pela análise de variância e as médias comparadas pelo teste de Tukey, e os dados quantitativos serão analisados pela regressão empregando-se o software SISVAR.

\section{Resultados e Discussão}

\section{Área foliar}

A densidade de 14 plantas não favoreceu a área foliar das cultivares IAC 503, IAC 886 e Tatu st, sendo, portanto não indicada quando o objetivo do plantio for voltado também para a produção de fitomassa.

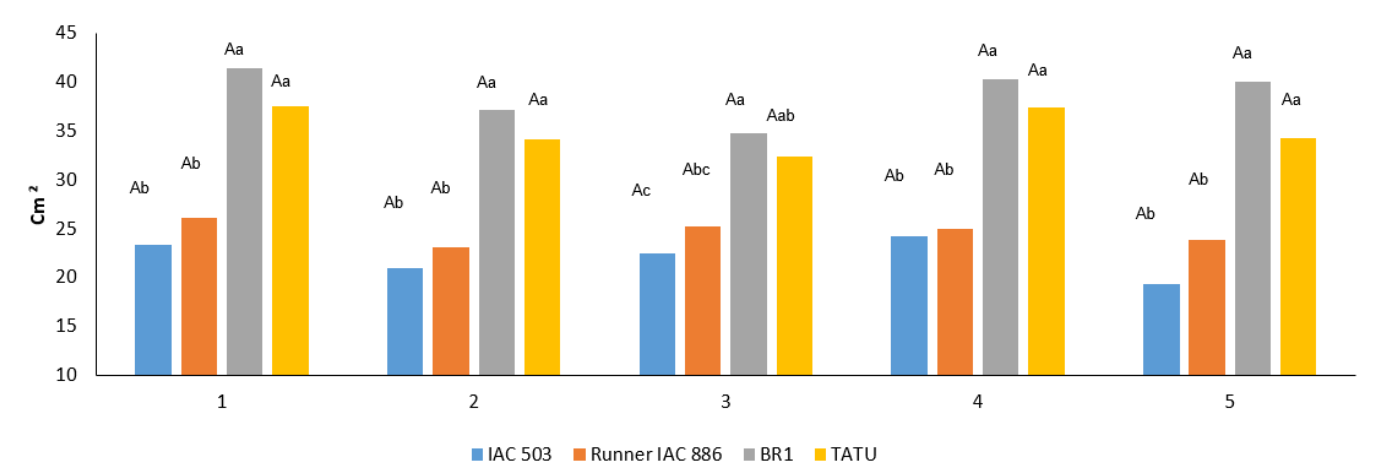

Figura 1. Área foliar de quatro cultivares testadas em cinco densidades de plantio.

\section{Altura de planta}

As cultivares de porte ereto (BR1 e Tatu st) são favorecidas na densidade de 20 plantas por metro, aumentando significativamente sua altura, resultado também obtido por Bellettini \& Endo (2001) em experimento com a cultivar Tatu vermelha. $\mathrm{O}$ oposto ocorreu na densidade de 8 plantas com menor registro de altura. 
Tal efeito pode ser explicado pelo sombreamento lateral causado pela proximidade das plantas, ocasionando estiolamento da haste principal por ter maior contato com a luz solar.

Tendo em vista que o amendoim é uma planta de crescimento indeterminado, deve haver controle no manejo para que os fotoassimilados sejam translocados de forma eficiente em toda a planta, pois a fase reprodutiva e vegetativa ocorre respectivamente e o crescimento vegetativo exagerado pode acarretar uma diminuição de produção, ou seja, de frutos.

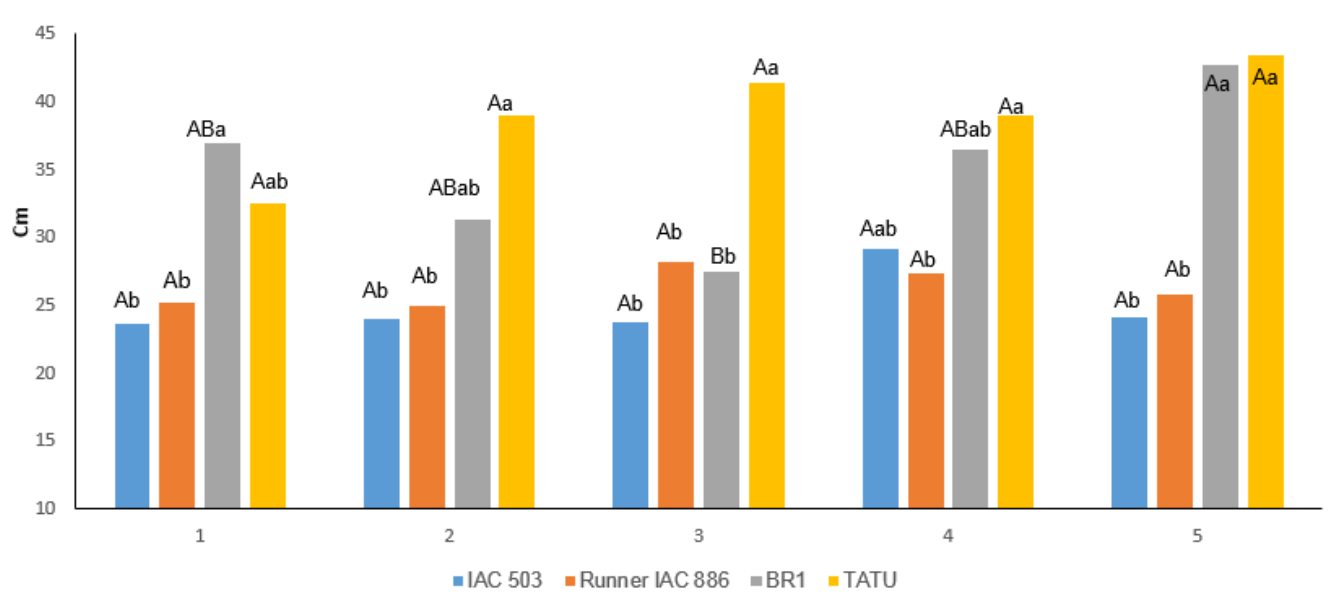

Figura 2. Altura de planta de quatro cultivares testadas em cinco densidades de plantio

\section{Ginóforo}

O número de ginóforos aumenta com o aumento da densidade. Com isso, a produção tende a aumentar, fato que pode ser explicado pela quantidade de fotoassimilados produzidos na haste principal, resultados diferentes foram encontrados por Bellettini \& Endo (2001), onde o aumento da densidade diminuiu o número de ginóforos. 


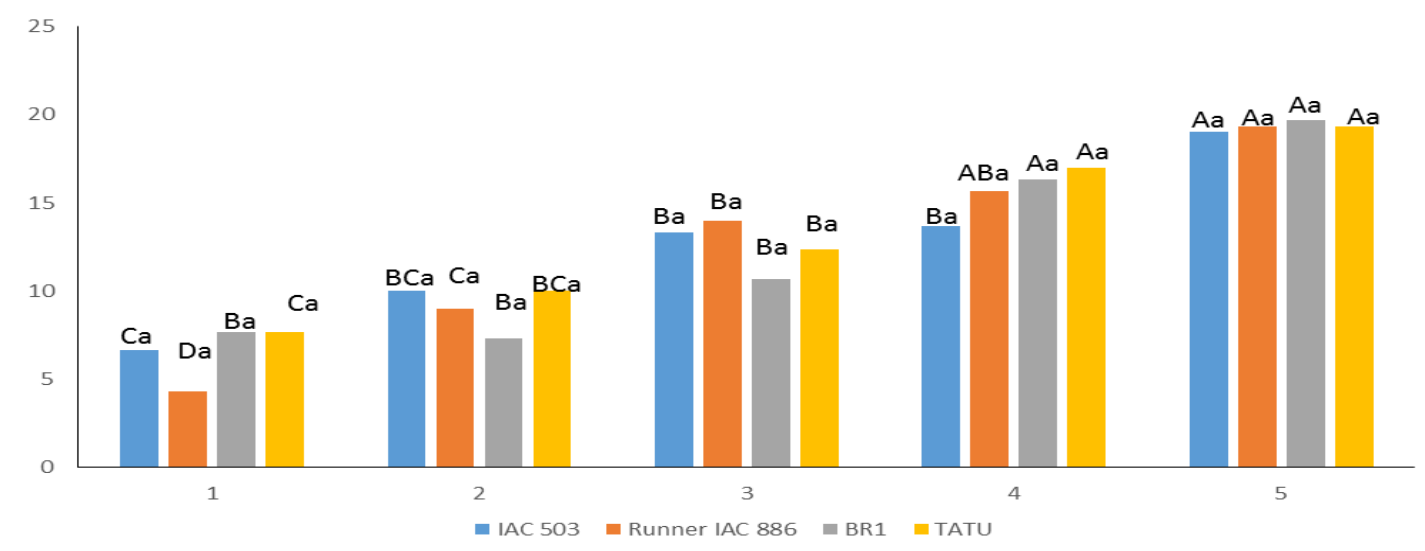

Figura 3. Número de ginóforos de quatro cultivares testadas em cinco densidades de plantio.

\section{Produtividade (Kg/ha)}

O corte associado à densidade de 8 plantas teve influência positiva na produtividade da cultivar IAC 886, onde o número menor de plantas pode ter tido melhor aproveitamento dos nutrientes do solo, além do estímulo do corte, direcionando a energia que seria utilizada na parte aérea para a produção dos frutos.

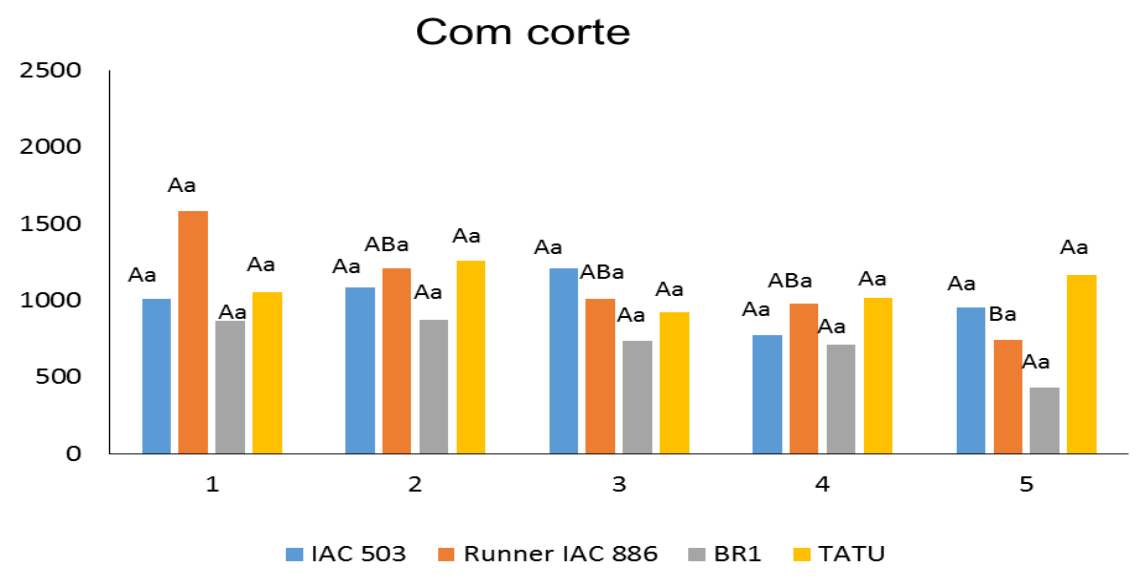

Figura 4. Produtividade de quatro cultivares testadas em cinco densidades de plantio e corte.

Já as plantas sem corte não apresentaram resultados significativos entre as cultivares nas densidades, no entanto a cultivar IAC 886 se sobressaem nas densidades de 8,11 e 17 plantas por metro. 


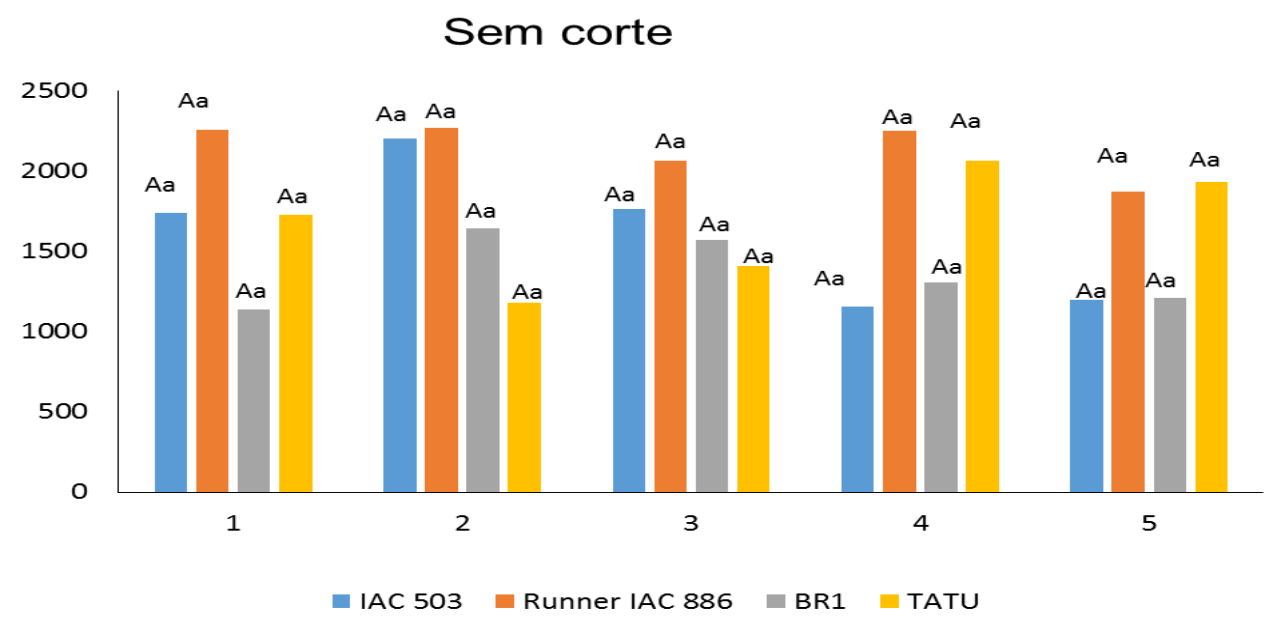

Figura 5. Produtividade de quatro cultivares testadas em cinco densidades c plantio e sem corte.

\section{Conclusões}

O aumento da densidade proporciona melhores parâmetros produtivos e fisiológicos na planta, associado ao corte possibilita o uso de todas as partes da planta, que mostra ser uma alternativa para os produtores, onde a fitomassa pode ser usada em diversos setores, seja na alimentação animal, seja na fertilidade do solo. Outros estudos devem ser realizados para que se tenha uma precisão da associação densidade e corte para o aumento da produtividade. 


\section{Referências}

ARGENTA, Gilber; SILVA, Paulo Regis Ferreira da and SANGOI, Luís. Arranjo de plantas em milho: análise do estado-da-arte. Cienc. Rural [online]. 2001, vol.31, n.6, pp.1075-1084. ISSN 1678-4596. http://dx.doi.org/10.1590/S010384782001000600027

BELLETTINI, Nair Mieko Takaki; ENDO, Romeu Munashi. Comportamento do amendoim das águas, Arachis hypogaea L., sob diferentes espaçamentos e densidades de semeadura. Acta Scientiarum. Agronomy (Online), v. 23, p. 1249-1256, 2001. https://doi.org/10.4025/actasciagron.v23i0.2627

FLOSS, Elmar Luiz. Fisiologia de plantas cultivadas: o estudo que está por trás do que se vê. Passo Fundo: UPF, 2004. 536p.

FREITAS, S. M.; MARGARIDO, M. A.; NEGRI NETO, A. Modelo de previsão para área plantada com amendoim das águas no estado de São Paulo. Informações Econômicas, São Paulo, v. 33, n. 2, p. 21-27, fev. 2003.

MARTINS, Renata. CULTIVARES DE AMENDOIM: um estudo sobre as contribuições da pesquisa pública paulista. Informações Econômicas, SP, v. 36, n.5, maio 2006.

NOGUEIRA JÚNIOR, S. Evolução da produção e comercialização de amendoim no Brasil. In: simpósio nacional y latinoamericano de oleaginosas, 8 , Buenos Aires, 1976.

MAUAD, Munir et al. Influência da densidade de semeadura sobre características agronômicas na cultura da soja. Revista Agrarian, Dourados, v. 3, n. 9, p. 175181, 2010. http://ojs.ufgd.edu.br/index.php/agrarian/article/view/75/649

RAMOS, Walquíria Bigatão. et al. Efeito do espaçamento e da população de plantas no desenvolvimento da canola. $1^{\circ}$ Simpósio Latino americano de canola. 2014, Passo Fundo, RS, Brasil.

TOLEDO, Márcia Ribeiro; TANCREDI, Fábio Daniel; SEDIYAMA, Tuneo; RIBEIRO JÚNIOR, José Ivo; REIS, Múcio Silva. Remoção do meristema apical e adensamento em plantas de soja visando sua utilização no método descendente de uma única semente. Acta Scientiarum. Agronomy, Maringá, v. 31, n. 1, p. 113-119, 2009. http://dx.doi.org/10.4025/actasciagron.v31i1.6656 